www.jmscr.igmpublication.org Impact Factor 5.244

Index Copernicus Value: 5.88 ISSN (e)-2347-176x ISSN (p) 2455-0450 crossref DOI: http://dx.doi.org/10.18535/jmscr/v4i5.15

Journal Of Medical Science And Clinical Research

\title{
Comparision of Maternal and Neonatal Outcomes in Outlet Forceps and Vacuum Extraction Deliveries
}

\author{
Authors \\ Dr Chaitra Ramachandra ${ }^{1}$, Dr Roopa ${ }^{2}$, Dr Rekha ${ }^{3}$, Dr Shankaregowda ${ }^{4}$, \\ Dr Nirupama.Y.S \\ 1,2,3 Assistant Professor, Department of Obstetrics and Gynaecology, BGS-GIMS \\ ${ }^{4}$ Professor and HOD, Department of Obstetrics and Gynaecology, BGS-GIMS \\ ${ }^{5}$ Consultant Obstetrician and Gynaecologist, Shanbhag Hospital, Bangalore \\ Corresponding Author \\ Dr Chaitra Ramachandra \\ BGS Global Hospital and Medical College, Kengeri, Bangalore, India \\ Email-drchaitraramachandra@gmail.com
}

\begin{abstract}
:
Aims: To compare the maternal and neonatal out come between forceps and vacuum extractions deliveries.

Methods and materials: A total of 100 patients were retrospectively analysed to compare the outcome between forceps $(N=50)$ and vacuum application $(N=50)$ between January 2015 to December 2015 in a tertiary care hospital. The indications for instrumental delivery were fetal distress, failure of descent of head, to cut short second stage of labor, poor maternal efforts. Maternal outcomes were analysed in terms of genital tract injuries (vaginal tears, cervical tears) perineal hematoma, paraurethral tears, postpartum hemorrhage. Neonatal outcomes were analysed in terms of APGAR scores), neonatal trauma (bruise marks, clavicular fractures), Cephalhematoma, Respiratory Distress Syndrome, NICU admissions. and neonatal mortality. The 2 groups were compared using paired T test with $p<0.05$ is statistically significant. The data were analysed using SPSS soft ware version 16.
\end{abstract}

Results: The most common age group in both the groups were between 21-29 years. Primigravida women with gestational age between 37-40 weeks more commonly required instrumental delivery in both the groups. Fetal Distress was the most common indication(42\%) for vaccum application and poor maternal efforts (36\%) is the most common indication for forceps. The maternal morbidity was higher in forceps compared to vacuum (58\% Vs .40\%). Amongst maternal morbidities seen, genital tract injuries (perineal laceration, episiotomy extension and cervical tears) were most common both arms but more in forceps arm which is statistically significant. Amongst the fetal morbidity noted, Neonatal Trauma (Bruises, abrasion, clavicular fracture) was more common in forceps application comparative to vacuum (16\% Vs 2\%). Cephalhematoma was noted only with vacuum applications (12\% Vs $0 \%$ ). NICU admission was significantly more in forceps application compare to vacuum (32\% Vs 24\%).

Conclusion: Vaccum application has a better maternal and neonatal outcome compared to forceps delivery, except cephalhematoma in the neonate which is increasing seen with vaccum application.

\begin{tabular}{ll} 
Introduction & the caesarean section rate. The $2^{\text {nd }}$ stage of labour \\
Instrumental vaginal deliveries is an integral & is a dynamic event and may require assistance. \\
component for skilled obstetric care which & Assisted vaginal delivery is conducted with the \\
improves outcome of vaginal delivery and reduces & use of forceps or ventouse (vaccum assisted \\
\hline
\end{tabular}


vaginal delivery) Vaginal delivery being assisted by instruments can either be vacuum extraction or forceps, a choice based on obstetrician's competence and training ${ }^{1}$. James Young Simpson was the first to use traction to deliver the baby. It was later modified by Malstrom in 1953. The obstetric forceps had its history from the time of Chamberlain family in the seventh century.

Assisted vaginal delivery, with the use of forceps or vacuum/ventouse, offers the option to accomplish safe delivery for the mother and the clinician. Modern obstetrics practice has witnessed an increase in the caesarean section rates everywhere. WHO recommends $10-15 \%$ caesarean section rate to achieve optimal maternal and neonatal safety. A successful assisted vaginal delivery avoids caesarean section, its attendant uterine scar and its implications for future pregnancy. Modern obstetric practice has witnessed an increase in the caesarean section trend. Reintroduction of this art-operative vaginal delivery will definitely find a place in emergency obstetric care. This study was designed to assess the maternal and neonatal outcome of vaccum and forceps assisted vaginal deliveries.

\section{Material and Methods}

This is a retrospective observational study which was carried out in the department of Obstetrics and Gynecology, BGS Global Institute of Medical
Sciences, Bangalore over a period of one year from January 2015 to December 2015. Fifty consecutive cases of forceps and ventouse deliveries each (total 100cases, 50 forceps and 50 ventouse deliveries) over this period were included, all of which were singleton pregnancies with fetus in cephalic presentation. The forceps used was Wrigley's outlet forceps and for vacuum extraction silastic $40 \mathrm{~mm}$ and $60 \mathrm{~mm}$ cups were used. The negative pressure applied was up to $0.6 \mathrm{~kg} / \mathrm{cm}$.

Right mediolateral episiotomy and perineal infiltration (lignocaine) was done as a routine. Cases were scrutinized for demographic data, gestational age and indication for instrumental delivery. The various indications for instrumental delivery were fetal distress, failure of descent of head, to cut short second stage of labor, poor maternal efforts. Maternal outcomes were analysed in terms of genital tract injuries (vaginal wall tear, cervical tear) perineal hematoma, paraurethral tears, postpartum hemorrhage, Neonatal outcomes were analysed in terms of APGAR scores), neonatal trauma (bruise marks, clavicular fractures), Cephalhematoma, Respiratory Distress Syndrome, NICU admissions. and neonatal mortality. The 2 groups were compared using paired $\mathrm{T}$ test with $\mathrm{p}<0.05$ is statistically significant. The data were analysed using SPSS soft ware version 16.

\section{Results}

Table 1: Comparision of Demographic Profile in both the groups

\begin{tabular}{|l|c|c|}
\hline & Vaccum $(\%)$ & Forceps $(\%)$ \\
\hline Maternal Age & & $08(16)$ \\
\hline$\leq 20$ years & $10(20)$ & $31(62)$ \\
\hline $21-29$ years & $32(64)$ & $11(22)$ \\
\hline$\geq 30$ years & $08(16)$ & $28(56)$ \\
\hline Parity & & $22(44)$ \\
\hline Primigravida & $31(62)$ & \\
\hline Multigravida & $19(38)$ & $31(62)$ \\
\hline Gestational Age & & $19(38)$ \\
\hline $37-40$ weeks & $27(54)$ & \\
\hline$>40$ weeks & $23(46)$ & instrental \\
\hline
\end{tabular}

The most common age group in both the groups were between 21-29 years. Primigravida women commonly required instrumental delivery in both with gestational age between 37-40 weeks more the groups as shown in table no 1 . 
Table 2: Indication for Application

\begin{tabular}{|l|c|c|}
\hline & Vaccum(\%) & Forceps(\%) \\
\hline Fetal Distress & $21(42)$ & $17(34)$ \\
\hline Poor Maternal efforts & $16(32)$ & $18(36)$ \\
\hline Prolonged 2 ${ }^{\text {sd }}$ stage of labour & $04(8)$ & $08(16)$ \\
\hline Failure of Descent & $03(6)$ & $01(2)$ \\
\hline To cut short 2nd stage of labour & & \\
\hline Severe Anaemia & $02(4)$ & $03(6)$ \\
\hline Severe PIH & $01(2)$ & $02(4)$ \\
\hline Cardiac Disease & $01(2)$ & $01(2)$ \\
\hline VBAC & $02(4)$ & -- \\
\hline
\end{tabular}

Fetal Distress was the most common maternal efforts (36\%) is the most common indication(42\%) for vaccum application and poor indication for forceps as shown in table no 2 .

Table 3 : Maternal Outcome

\begin{tabular}{|l|l|l|}
\hline & Vaccum(\%) & Forceps $(\%)$ \\
\hline Normal laceration/Episiotomy & $30(60)$ & $21(42)$ \\
\hline $\begin{array}{l}\text { Perineal } \\
\text { extension/Cervical tears }\end{array}$ & $14(28)$ & $19(38)$ \\
\hline Perineal Hematoma & 00 & $2(4)$ \\
\hline Para urethral lacerations & $02(4)$ & $2(4)$ \\
\hline Post Partum hemarrhage & $4(8)$ & $6(12)$ \\
\hline
\end{tabular}

The maternal morbidity was higher in forceps compared to vacuum (58\% Vs .40\%). Amongst maternal morbidities seen, genital tract injuries (perineal laceration, episiotomy extension and cervical tears) were most common both arms but more in forceps arm which is statistically significant as shown in the table no 3. There were no maternal mortality seen in both the arm.

Table 4: Neonatal Out come

\begin{tabular}{|l|l|l|}
\hline & \multicolumn{1}{|c|}{ Vaccum(\%) } & \multicolumn{1}{|c|}{ Forceps (\%) } \\
\hline Normal Baby & $26(52)$ & $16(32)$ \\
\hline Low APGAR & & \\
\hline$<4$ at 1 minutes & $1(2)$ & $4(8)$ \\
\hline$<7$ at 5 minutes & $4(8)$ & $6(12)$ \\
\hline $\begin{array}{l}\text { Neonatal Trauma: Bruises/abrasion/ } \\
\text { Clavicular fracture }\end{array}$ & $1(2)$ & $8(16)$ \\
\hline Cephalhematoma & $6(12)$ & 0 \\
\hline NICU admission/ RDS & $12(24)$ & $16(32)$ \\
\hline
\end{tabular}

RDS- Respitarory Distress Syndrome, NICU- Neonatal Intensive care Unit.

Amongst the fetal morbidity noted, Neonatal Trauma (Bruises, abrasion, clavicular fracture) was more common in forceps application comparative to vacuum (16\% Vs $2 \%)$. Cephalhematoma was noted only with vacuum applications (12\% Vs $0 \%$ ). NICU admission was significantly more in forceps application compare to vacuum (32\% Vs 24\%) as shown in table no 4.

\section{Discussion}

In our study primigravida women with gestational age between 37-40 weeks more commonly required instrumental delivery in both the groups (vaccum and forceps) a finding similar to the reported rates in an earlier studies ${ }^{6}$. Episiotomy was given as a routine in all the patients. Fetal Distress was the most common indication (42\%) for vaccum application and poor maternal efforts $(36 \%)$ is the most common indication for forceps. 
In a study in Texas University the most common indication was fetal compromise and failure to deliver spontaneously with maximum maternal effort, which agrees with our present study. Our findings differed from Singh A et al, where cutting short of second stage of labor was the chief indication followed by prolonged 2 nd stage of labour ${ }^{9}$.

In our study maternal morbidity was higher in forceps compared to vacuum (58\% Vs $.40 \%)$. Amongst maternal morbidities seen, genital tract injuries (perineal laceration, episiotomy extension and cervical tears) were more common in both the groups but more in forceps application which is statistically significant. There were no maternal mortality seen in both the groups Johnson et al reported a high incidence of maternal third and fourth degree perineal lacerations and vaginal lacerations with the use of forceps ${ }^{10}$. While a study in Cameroon reported only minor cervical and vaginal lacerations in cases of instrumental deliveries ${ }^{11}$.

Regarding neonatal outcome, neonatal trauma (Bruises, abrasion, clavicular fracture) was more common in forceps application comparative to vacuum $(16 \%$ Vs $2 \%)$ In our study cephalhematoma was noted only with vacuum applications (12\% Vs $0 \%$ ). NICU admission was significantly more in forceps application compare to vacuum (32\% Vs 24\%). A review of the literature yields divergent views about the effects of vacuum extraction on the newborn. However, most authors agree that serious neonatal injuries are rare with vacuum extraction ${ }^{6,8,10,12}$. Neonatal well-being assessed by Apgar scores was no different among the two groups, consistent with other reports ${ }^{4,6,9,10}$.

\section{Conclusion}

Our study concludes that in need of instrumental delivery, vaccum application has a better maternal and neonatal outcome compared to forceps delivery, except cephalhematoma in the neonate which is increasing seen with vaccum application.

Conflict of interest: None

\section{References}

1. Editorial. Vacuum versus Forceps. Lance. 1984 Jan 21;(8639):144

2. Lomas J, Enkin M. Variations in operative delivery rates. In: Chalmers I, Enkin M, Keirse MNJC, eds. Effective care in preg and child birth. Vol. 2. Oxford, England: Oxford University Press, 1991:1182-95

3. Johanson RB, Vacuum extraction vs forceps delivery. Oxford, England: The Cochrane library: pregnancy and the childbirth database, 2000

4. Johanson RB, Rice C, Doyle M, et al. A randomized prospective study comparing the new vacuum extractor policy with forceps delivery. $\mathrm{Br} \quad \mathrm{J}$ Obstet Gynaecol.1993;100(6):524-30

5. Giri A, Vaidya A. Maternal and fetal outcomes of vacuum assisted delivery. Postgradua te Medical journal of National Academy of Medical Sciences. 2008;8(1):48-56

6. Prapas N, Kalogiannidis I, Masoura S, et al. Operative vaginal delivery in singlrton term pregnancies: short -term maternal and neonatal outcomes. Hippokratia.2009 Jan;13(1):41-5

7. Akhtar S. Comparison of maternal and infant outcomes between vacuum extraction and forceps deliveries. Pakistan Armed forceps journal.2006;2(1):25-31

8. Mesleh RA, AL Sawadi HM, Kurdi AM. Comparison of maternal and infant outcomes between vacuum extract ion and forceps deliveries.Saudi Medical journal. 2002;23(7):811-3.

9. Achanna S, Monga D. Outcome of forceps delivery versus vacuum extraction a review of 200 cases. Singapore Med J. 1994 Dec;35 (6):605 -8

10. Caeter J.The vacuum extractor. In stud $\mathrm{J}$ (Editor).Progress in Obstetrics and Gynaecology. London: ChurchillLivingstone. 1990;8:107-26

11. Johnson JH, Figueroa R, Garry D,Ellimian A, Maulik D. immediate maternal and 
neonatal effects of forceps and vacuum assisted deliveries. Obstet Gynaecol.2004: 103(3):513-8

12. Gachiri JR, Rogo KO. Foetal and maternal outcome of vacuum extraction. East Afr MedJ.1991;68(7):539-46.

13. Baker PN.The place of Mid forceps deliveries in the modern obstetric practice. Current Obst and Gynaec.1995;5:225-9

14. Baskett TF, Fanning CA,Young DC. A Prospective observational study of 1000 vacuum assisted deliveries with the omni cup device. J ObstetGynaecol Can.2008; 300(7):573 -80 